\title{
Chronic Back Pain Suspected Sacroiliitis, Seronegative-Spondyloarthropathy related Sacroiliitis: Features and Differentials
}

\author{
Dejan Spasovski* \\ University Clinical Center-Mother Therese, Skopje, Republic of North Macedonia.
}

\begin{abstract}
Introduction: Very often late diagnosis in spondylitis ankylosans (SA) in the period between 5 to 10 years is due to unstandardized diagnostic method besides established diagnostic criteria. But they are very restrictive and not practical for early diagnosis of SA, because are based on proved radiographic changes.

Aim: Sacroiliitis (SI) as a sole entity rarely exists, usually is a part of a diagnostic mosaic of SA and related spondyloarthropathies (SpA). Surely proved SI clinically and radiographically means sure diagnosis of SA, especially in the early stage of the disease.

Material and Methods: Highly selective group of patients with SA was followed in the period of one year: group of 23 patients (pts) with unconvincing radiographic changes for SA from $1-2^{\circ}$ and group of 21 pts without radiographic changes i.e. $0^{\circ}$. Beside SA, both groups fulfilled at least another from the listed conditions: 1 . Oligoarthritis; 2 . Enthesitis; 3 . Iridocyclitis; 4. Positive family history for SA; 5. Positive antigen HLA-B27 and 6. Elevated ESR $>30 \mathrm{~mm} / \mathrm{h}$.

Results: after observational period of one year in the group A 11/21 pts were with SA. In the group B only 6/23 pts were with SA; the others were transformed in different directions: $4 / 23$ in the group of spondyloarthropathies (SpA) -2 pts with Psoriatic spondyloarthropathy (PsSpA), 1 patient with Reiter syndrome (RS)and 1 patient with Entericspondyloarthropathy (ESpA). The others $8 / 22$ pts were still undefined SpA.

Conclusion: Our results showed that defining of SA was crucial in the diagnosis of SA. The fact that most of cases with authentic SA were in group A with minimal radiographic changes from $1-2^{\circ}$ in comparison with group B without radiographic changes showed the necessity of using other imaging techniques (scan, MRI) for earlier detection of SI in the so called pre-radiographic stage which lasts 2-4 years, when radiographic findings are absent. Clinical (symptomatic) SI without radiographic changes according to the findings of pts in the group B gives a possibility for overlap to other entities in the group of SpA.
\end{abstract}

\section{KEYWORDS}

Spondyloarthropathies, Sacroileitis, Spondylitis ankylosans

Correspondins Author Information

Dejan Spasovski

University Clinic of Rheumatology, University Clinical Center-Mother Therese, Skopje, Republic of North Macedonia, Tel: +389023147668 .

Received: March 04, 2020; Accepted: March 24, 2020; Published: March 30, 2020

Copyright: (C) 2020 ASRJS. This is an openaccess article distributed under the terms of the Creative Commons Attribution 4.0 International license.

Citation: Dejan Spasovski. Chronic Back Pain Suspected Sacroiliitis, Seronegative-Spondyloarthropathy related Sacroiliitis: Features and Differentials. Med Clin Res Open Access, 2020;1(1):1-5. 


\section{Introduction}

Spondyloarthropathies (SpA) are group of diseases with common clinical features and are carriers of the genetic marker - antigen HLA-B27 in high percentage. Main representative is Spondylitis ankylosans (SA), but there are also Reiter syndrome-reactive arthritis (RS), Psoriatic spondyloarthropathy (PsSpA) and undefined spondyloarthropathies (SpA). SA is chronic progressive inflammatory disease with unknown etiology. It is usually seen in young people between 25 and 35 years of age with the domination of males. All these entities have similar clinical features and presence of the antigen HLA-B27 in high percentage 70-95\%.

\section{Materials and Methods}

In patients included in this study disease diagnosis was based on modified New York criteria (1984), graded by Hart and Robinson, proposed by the American Association for Rheumatism (ARA) for diagnosis of SA. They are rather restrictive, based on secure radiographic changes. They are used for epidemiological studies and not for clinical use, because they don't encompass the whole spectrum of SA. Clinical assessment of the disease activity and disease diagnosis was made by subspecialist. For diagnosis of Psoriatic spondyloarthropaty were used diagnostic criteria by Moll-Wright for classification of Psoriatic arthritis. They were dermatologically tested, including examination of psoriatic changes, nails, psoriatic areas as well as an index for disease activity (PASI) and evaluation of peripheral and axial joints. The diagnosis of oligoarthritis was made when $<5$ joints were involved, polyarthritis when $>5$ joints were involved. Diagnosis of symmetric arthritis was made when there was bilateral involvement of $>50 \%$ of joints.

In this study were included 23 pts (7 women, 16 men) with SI with unconvincing radiographic changes for $\mathrm{SA}$ from $1-2^{\circ}$ and a group of 21 pts ( 9 women, 12 men) without radiographic changes i.e.SA $0^{\circ}$. The mean age in the first group was 27,28 years $(( \pm 8,09)$ (range 25 -40years), while in the second group was 29,35 years $( \pm 9,24)$ (range 28-44 years).

Mean duration in months from the beginning of disease is 7,27 ( \pm 6,12 ). Patients did not take any previous medication that would modify the course of the disease like sulphasalazine, methotrexate, leflunamide. The samples were collected in the period of one year. In the group of 23 pts with unconvincing radiographic changes for SA we expected to find authentic cases of SA in the early stages of disease.

\section{Including criteria}

In this study were included newly diagnosed patients suffering from sacroiliitis, aged 18-45 years, previously untreated.

\section{Excluding criteria}

All patients with diseases or conditions that could directly or indirectly affect the results were excluded from this study:

- Pts with previous history of diseases of the spleen, thyroid gland, liver damages, renal, hematological, hart, neurological, lung disorders, autoimmune diseases, AIDS, aged $<18$ years.

- Pts with diabetes mellitus, acute infections, malignant diseases, febrile conditions.

- Pts previously treated with antibiotics and salicylatesin the period less than 6 months from the beginning of the study.

- Pts with hyperyension, uric arthritis, urinary infections, SLE, Sjogren syndrome, mixed conective tissue disease, vasculitis.

- Pts treated with antihypertensive drugs, antidiabetic medications and cardiological drugs.

- Pts with history of blood transfusions and overweight pts.

- Pts with medications from the base line.

- Pts with acute and chronic renal failure.

All patients voluntarily participated in this study, so the ethic criteria were fulfilled.

Laboratory assessment

For clinical assessment of the basic disease the following laboratory variables were necessary to be taken into account: complete blood count (CBC), differential blood count, reactants of the acute phase, ACPA antibodies, C-reactive protein (CRP), Rheumatoid arthritis (RA), erythrocyte sedimentation rate (ESR), alkaline phosphatase (AP), aspartate aminotransferase (AST), alanine aminotransferase (ALT), creatine kinase (CK), lactate dehydrogenase (LDH), serum urea, serum creatinine.

CRP was determined with agglutination test (Latex CRP test) (BioSystem S.A. reagent \& instruments Costa Brava 30, Barcelona (Spain). Reference values for CRP in serum are $<6 \mathrm{mg} / \mathrm{L}$. RF was determined with agglutination test (Latex CRP test) (BioSystem S.A. reagent \& instruments Costa Brava 30, Barcelona (Spain). Referent values for $\mathrm{RF}$ in serum are $<30 \mathrm{IU} / \mathrm{ml}$. For ESR quantitative Westergren test was used. Referent values for men are 7-8 мм, for women 11-16 мм.

ACPA antibody was determined with semi-quantitative/qualitative ELISA method, from manufacturer. Dia-statTM (Axis-Shield Diagnostic), based upon detection of IgG antibodies in human serum/plasma directed towards synthetic cyclic citrullinated peptides that comprise modified arginine residua. Calculation and interpretation of the results for the quantitative protocol is estimated from the absorbent value (optic density) from positive and negative control, for every sample.

\begin{tabular}{|c|c|}
\hline Absorbent value & Interpretation of the results \\
\hline$<0.95$ & negative \\
\hline$>0.95<1.0$ & Borderline value \\
\hline$>1.0$ & positive \\
\hline
\end{tabular}

Statistical analysis

For testing the significance of differences between two arithmetic means, i.e. proportions in comparison of the values of certain numerical parameters between two groups Wilcoxon- matched test for independent samples was used. P value between 0,05 and 0,1 was considered statistically significant. Data processing was 
made with Statistical package Statistica7.0

\section{Results}

In the group with 21 pts with SA 1 patient showed presence of ACPA antibodies, while RF was not find in any patient. In the group withsacroiieitis no patient was ACPA positive, while 1 patient was RF positive (Table 1).

Table 1: ACPA antibodies in Spondylitis ankylosans and Sacroileitis.

\begin{tabular}{|c|c|c|}
\hline & $\begin{array}{c}\text { Spondylitis ankylosans } \\
\text { Group N } 21\end{array}$ & $\begin{array}{c}\text { Sacroileitis } \\
\text { Group N } 23\end{array}$ \\
\hline & Positive / Negative & Positive / Negative \\
\hline $\mathrm{ACPA}+>1,26$ & $1 / 21$ & $0 / 23$ \\
\hline $\mathrm{RF}+30>\mathrm{IU} / \mathrm{ml}$ & $0 / 21$ & $1 / 22$ \\
\hline $\mathrm{CRP}+12>\mathrm{mg} / \mathrm{L}$ & $16 / 5$ & $7 / 16$ \\
\hline $\mathrm{ESR}+>16$ & $18 / 3$ & $15 / 8$ \\
\hline
\end{tabular}

1. There was statistical correlation using Wilcoxon- matched test between ACPA in SA and SI forp $<0.05$ ( $p=0.01)$.In the group with SA there was statistical correlation between ACPA and RF for $\mathrm{p}<0.05(\mathrm{p}=0.00)$, ACPA and CRP $(\mathrm{p}=0.00)$.

2. There was no statistical correlation using Wilcoxon- matched test between ACPA in SA and age, disease duration in months, RF and CRP in the same group for $p<0.05$. (ACPA versus age $p=0.04$; ACPA versus disease duration in months $\mathrm{p}=0.07$, ACPA versus $\mathrm{RF}$ $\mathrm{p}=0.02$, ACPA versus CRP $\mathrm{p}=0.05$ (Figure 1).

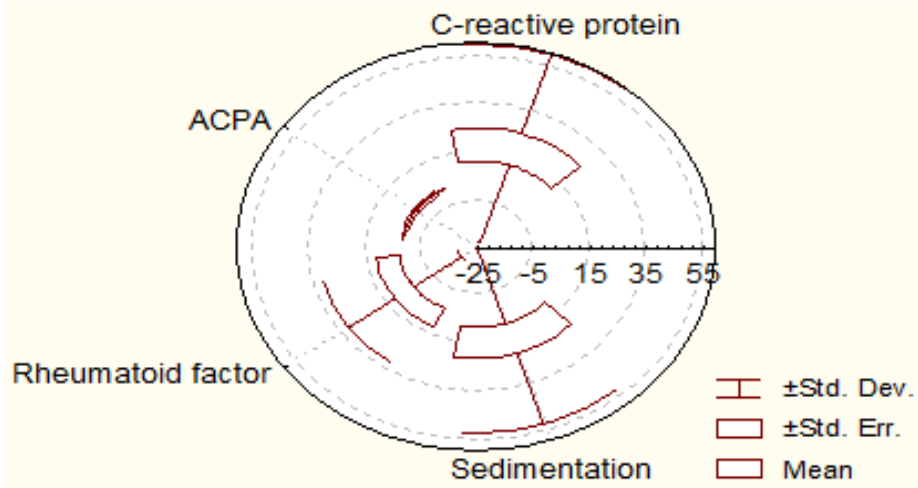

Figure 1: Distribution of ACPA, RF and CRP in SI group.

\section{Discussion}

AccordingtotheconceptoftheEuropean studyspondyloarthropathy group - ESSG (1991), the leading inclusion criterion is presence of spondylitis or oligoarthritis (1-7). If this criterion is fulfilled follow: 1. Positive family history; 2 . Dermatological changes such as Psoriasis vulgaris; 3. Data for colitis or similar diseases (Crohn disease, Whipple disease); 4. Urethritis or cervicitis; 5. Diarrhea; 6. Alternate femoral pain (sacral); Enthesopathy; 8. Radiological prove for sacroiliitis.

If the patients fulfill this clinical-diagnostic mosaic there is possibility for "overlap" syndrome i.e. transition from one into other spondyloarthropathy. This basic concept in 1995 was accepted by the international expert group, formally for study of SA, later renamed ASAS (Assessment of SpondyloArthritis International Society) or International group for estimation of spondyloarthritis. It is obvious that the term spondyloarthritis prevail over the term $\mathrm{SpA}$, but time will show whether this will remain so.

In the last decade the international ASAS group (Germany, France, Netherlands, Mexico and Canada) supported by the bodies of EULAR (European Rheumatology Association) took a leading role in sublimation of all new knowledge in the field of SpA. Although main targets are in better definition of SA as a prototype or synonym for the group of $\mathrm{SpA}$, of no less importance is the research of undefined $\mathrm{SpA}$.

There was a try to reevaluate the current qualification criteria for diagnosis of SA and other SpA. A special accent was put on defining the inflammatory pain in the lumbar region and its distinction from mechanical pain in the same region. It would be the "key" in the detection of the early forms of SA (8-14).

Because the laboratory findings, including determination of the antigen HLA-B27, have not crucial diagnostic significance, the focus is made on the novel "imaging" techniques, among them nuclear magnetic resonance - MRI has a dominant place. The group Bath from Great Britain in the period 1994-98, in their epidemiologic and clinical research included one series of 5 questionnaire-indexes for SA, referring the follow up of the disease activity, functional capacity, radiographic progression and the effect of applied therapy. The validity of these questionnaires was proved by several authors, but their application is not yet widely accepted. They are not used in routine examination, and also not used in our country (15-21).

Similar tries and modifications of Bath indexes were made recently the ASAS group in term of follow up the SA activity, and especially in the management of therapy and follow up of qualitative and quantitative aspect. This especially relates to the follow up of the effects of biological therapy in SA as a turning point to the present insight that the disease is incurable and has its own natural course, upon which it is not possible to interfere (Image 1-3).

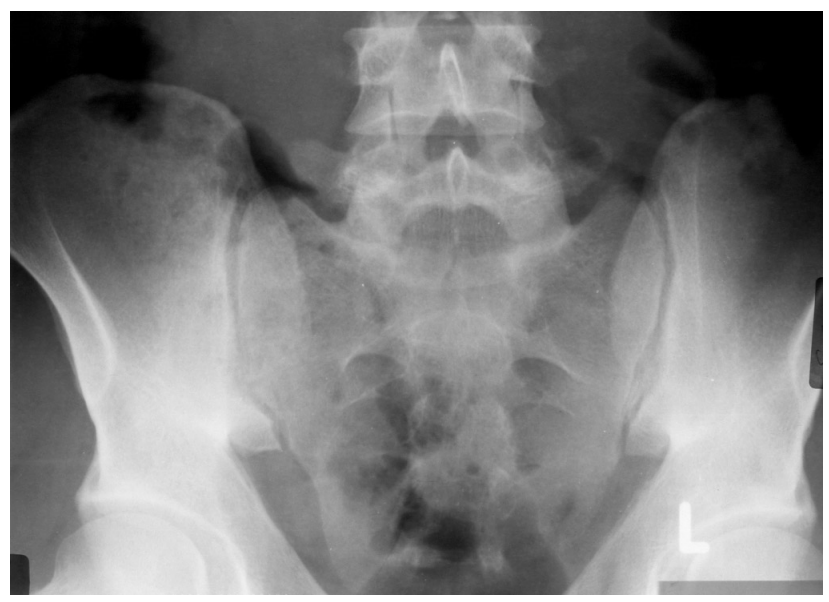

Image 1: Normal sacroiliac joints. 


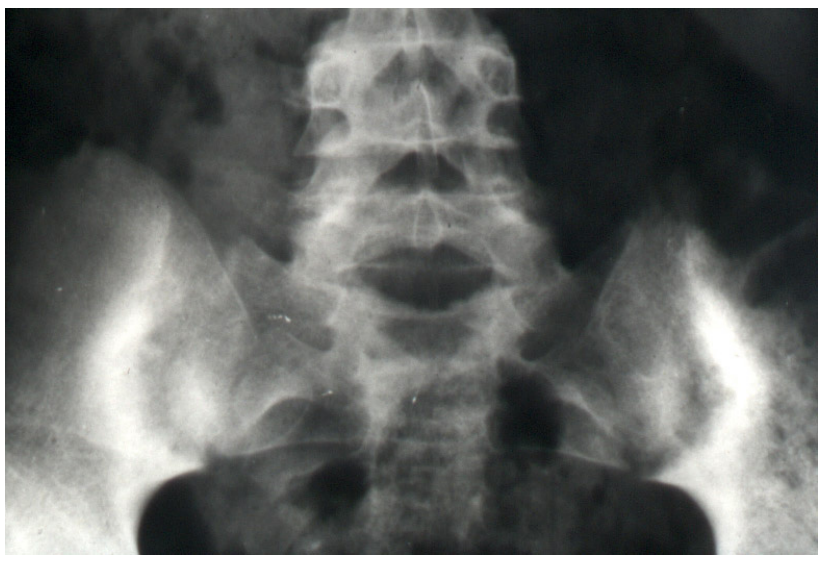

Image 2: Bilateral sacroiliitis.

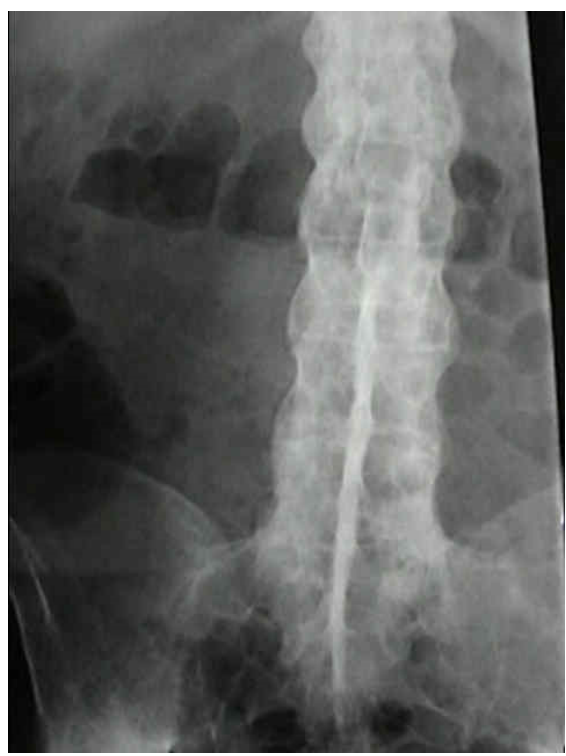

Image 3: Advanced form of Spondylitis ankylosans.

With this sophisticated therapy patients would have better control, stabilization of the process and stopping the disease in long term. All the new recommendations proposed by the experts of the ASAS group throw new light in the study of SpA as a significant segment in rheumatology, but time will show how wide will be the consensus for their acceptance/ application.

\section{Conclusion}

The fact that the prevalence of $\mathrm{SpA}$ is approximately $1 \%$ in common population with tendency to increase, shows the focus of interest towards this group. It hits mostly the young active population between 20-40 years of age with important implications in the functional capacity, working capacity and quality of life. Therefore, it is of crucial importance better knowledge of SpA and the use of contemporary diagnostic and therapeutic approach.

\section{References}

1. Dougados M, van der Linden S, Juhlin R, et al. The European Spondylarhropathy Study Group preliminary criteria for the classification of spondyloarthropathy. Arthritis Rheum,
1991;34:1218-227.

2. Rudwaleit M, van der Heijde D, Khan MA, et al. How to diagnose axial spondyloarthritis early. Ann Rheum Dis, 2004;63:535-543.

3. Zochling J, van der Heijde D, Burgos-Vargas R, et al. ASAS/ EULAR recommendations for the management of ankylosing spondylitis. Ann Rhum Dis, 2006;65:442-452.

4. Rudwaleit M, Khan MA, Sieper J. The challenge of diagnosis and classification in early ankylosing spondylitis: do we need new criteria? Arthritis Rheum, 2005;52:1000-1008.

5. van der Linden S, Valkenburg HA, Cats A. Evaluation of diagnostic criteria for ankylosing spondylitis. A proposal for modification of the New York criteria. Arthritis Theum, 1984;27:361-368.

6. Braun J, Kiltz U, Baraliakos X, et al. Optimisation of rheumatology assessments - the actual situation in axial spondyloarthritis including ankylosing spondylitis. Clin Exp Rheumatol, 2014;32:96-104.

7. Slobodin G, Eshed I. Non-Radiographic Axial Spondyloarthritis. Isr Med Assoc J, 2015;17:770-776.

8. Min HK, Cho H, Park SH. Baseline severity of sacroiliitis can predict acute inflammatory status of sacroiliac joint in early axial spondyloarthritis of male patients: a cross sectional study. BMC Musculoskelet Disord, 2019;20:144.

9. van der Heijde D, Baraliakos X, Hermann KA, et al. Limited radiographic progression and sustained reductions in MRI inflammation in patients with axial spondyloarthritis: 4-year imaging outcomes from the RAPID-axSpA phase III randomised trial. Ann Rheum Dis, 2018;77:699-705.

10. Kang KY, Jung JY, Hong YS, et al. Positive correlation between inflammation on sacroiliac joint MRI and serum C-terminal telopeptide of type-I collagen in ankylosing spondylitis but not in non-radiographic axial spondyloarthritis. Clin Exp Rheumatol, 2017;35:415-422.

11. Lorenzin M, Ortolan A, Frallonardo P, et al. Spine and sacroiliac joints on magnetic resonance imaging in patients with early axial spondyloarthritis: prevalence of lesions and association with clinical and disease activity indices from the Italian group of the SPACE study. Reumatismo, 2016;68:72-82.

12. Rumyantseva DG, Dubinina TV, Demina AB, et al. Ankylosing spondylitis and non-radiographic axial spondyloarthritis: Two stages of disease?. Ter Arkh, 2017;89:33-37.

13. Liao $\mathrm{Z}$, Lin $\mathrm{Z}$, $\mathrm{Xu} \mathrm{M}$, et al. Clinical features of axial undifferentiated spondyloarthritis (USpA) in China: HLA-B27 is more useful for classification than MRI of the sacroiliac joint. Scand J Rheumatol, 2011;40:439-443.

14. Raychaudhuri SP, Deodhar A.J. The classification and diagnostic criteria of ankylosing spondylitis. Autoimmun, 2014;48-49:128-133.

15. Landewé RB, van der Heijde DM. The recognition of patients with spondyloarthritis. New classification criteria. Ned Tijdschr Geneeskd, 2011;155(30-31):A3680.

16. Rudwaleit M, Taylor WJ. Classification criteria for psoriatic arthritis and ankylosing spondylitis/axial spondyloarthritis. Best Pract Res Clin Rheumatol, 2010;24:589-604.

17. Malaviya AN, Kalyani A, Rawat R, et al. Comparison of patients 
with ankylosing spondylitis (AS) and non-radiographic axial spondyloarthritis (nr-axSpA) from a single rheumatology clinic in New Delhi. Int J Rheum Dis, 2015; 18:736-741.

18. Ozgocmen S, Khan MA. Current concept of spondyloarthritis: special emphasis on early referral and diagnosis. Curr Rheumatol Rep, 2012;14:409-414.

19. Heuft-Dorenbosch L, Landewé R, Weijers R, et al. Performance of various criteria sets in patients with inflammatory back pain of short duration; the Maastricht early spondyloarthritisclinic.
Ann Rheum Dis, 2007; 66:92-98.

20. Proft F, Poddubnyy D. Ankylosing spondylitis and axial spondyloarthritis: recent insights and impact of new classification criteria. Ther Adv Musculoskelet Dis, 2018;10:129-139.

21. Raychaudhuri SP, Deodhar A. The classification and diagnostic criteria of ankylosingspondylitis. J Autoimmun, 2014; 4849:128-133. 